\title{
HMG17 is a chromatin-specific transcriptional coactivator that increases the efficiency of transcription initiation
}

\author{
Suman M. Paranjape, ${ }^{1,2}$ Anton Krumm, ${ }^{3}$ and James T. Kadonaga ${ }^{1,4}$ \\ ${ }^{1}$ Department of Biology, 0347, and Center for Molecular Genetics, ${ }^{2}$ Department of Biomedical Sciences, University of \\ California, San Diego, La Jolla, Calfornia 92093-0347 USA ${ }^{3}$ Fred Hutchison Cancer Center, Seattle, Washington 98104 USA
}

\begin{abstract}
We have examined the effect of HMG17 on transcription by RNA polymerase II by the assembly and analysis of HMG17-containing chromatin templates consisting of regularly spaced nucleosomal arrays. Structural analysis of the chromatin indicated that HMG17 is incorporated into chromatin in a physiological manner with the full complement of core histones. The transcriptional studies revealed that HMG17 stimulates transcription in conjunction with the sequence-specific activator GAL4-VP16. This effect was observed with chromatin, but not with non-nucleosomal templates, and required the presence of HMG17 during chromatin assembly. The incorporation of HMG17 into chromatin resulted in a 7- to 40-fold stimulation of GAL4-VP16-activated transcription to levels that were comparable to those observed with histone-free DNA templates. In contrast, transcription from HMG17-containing chromatin was not detectable in the absence of GAL4-VP16 or with a GAL4 derivative [GAL4(1-147)] lacking the VP16 activation domain. Finally, the incorporation of HMG17 into chromatin was found to increase the efficiency of transcription initiation, but not the extent of transcriptional elongation. Thus, HMG17 is a chromatin-specific transcriptional coactivator that increases the efficiency of initiation of transcription by RNA polymerase II.
\end{abstract}

[Key Words: Chromatin; HMG14/17; nucleosome assembly; RNA polymerase II; GAL4-VP16; in vitro transcription]

Received May 1, 1995; revised version accepted July 7, 1995.

In eukaryotes, the regulation of transcription by RNA polymerase II is determined not only by the action of transcription factors, but also by the structure of the chromatin template (for review, see van Holde 1989; Felsenfeld 1992; Wolffe 1992; Paranjape et al. 1994). The packaging of DNA into chromatin restricts the accessibility of the template to the transcriptional machinery, and promoter- and enhancer-binding factors function, at least in part, to counteract the chromatin-mediated repression. Thus far, studies of chromatin structure and gene activity have focused primarily on the function of the histones. These experiments have provided useful insight into the role of nucleosome structure in the regulation of transcription. Yet, to gain a more complete understanding of chromatin function, it will be necessary to investigate the properties of nonhistone chromosomal proteins, such as the high mobility group (HMG) proteins.

The HMG proteins were originally identified as small, nonhistone chromosomal proteins /with the exception of

${ }^{4}$ Corresponding author. ubiquitin) that can be extracted from nuclei with $0.35 \mathrm{M}$ $\mathrm{NaCl}$ and are soluble in $2 \%$ trichloroacetic acid (for review, see Goodwin et al. 1978; Goodwin and Mathew 1982; Einck and Bustin 1985; Bustin et al. 1990). There are three subclasses of HMG proteins: HMG1/2, HMG 14/17, and HMG-I/-Y. HMG proteins within each subclass are structurally related, whereas HMG proteins from different subclasses are unrelated. Hence, these proteins have been designated as "HMG proteins" on the basis of their extraction and solubility properties rather than a common structure or function.

In this work we have examined the effect of HMG17 upon the activation of transcription by RNA polymerase II. HMG14 and HMGl7 are small $(\sim 10 \mathrm{kD})$, highly charged proteins that interact with high affinity to two distinct sites in nucleosomal cores (Albright et al. 1980; Mardian et al. 1980; Sandeen et al. 1980; Shick et al. 1985; Cook et al. 1986; Crippa et al. 1992, 1993; Alfonso et al. 1994). Moreover, HMG14/17 proteins bind with higher affinity to core particles than to naked DNA (Sandeen et al. 1980). In addition, the binding of HMG14/17 increases the stability of core particles (Paton et al. 1983; Yau et al. 1983; Crippa et al. 1992). It is 
estimated that there is an average of $\sim 0.5$ molecule of HMG17 per 200 bp of DNA (Kuehl et al. 1984).

A variety of data have led to the postulate that HMG14/17 proteins are involved in transcriptional activation. Early work with nucleosomal core particles had suggested that HMG14/17 interact preferentially with chromatin of actively transcribed genes (for review, see Weisbrod 1982), but technical limitations of those experiments, which include the rapid exchange of HMG14/17 in vitro (Landsman et al. 1986) and variability in the binding of HMG14/17 to core particles (Swerdlow and Varshavsky 1983), had also led to some disagreement regarding the results. In other studies, an enrichment of HMG14/17 in active chromatin was observed by protein-DNA cross-linking ( $\sim 1.5$ - to 2.4 -fold enrichment; Postnikov et al. 1991) as well as by immunofractionation of oligonucleosomes with a monoclonal antibody against HMG17 ( 60- to 100-fold enrichment; Dorbic and Wittig 1987). These experiments did not, however, distinguish whether the enrichment of HMG17 had augmented gene activity or was a consequence of transcription. Biochemical experiments with SV40 minichromosomes had led to the conclusion that HMG14 stimulates transcriptional elongation but not initiation (Ding et al. 1994). In addition, studies of HMG17-containing chromatin templates had indicated that HMGl7 stimulates transcription by RNA polymerase III (Crippa et al. 1993; Trieschmann et al. 1995). Thus, the available data suggest a role for HMG14/17 in transcriptional regulation.

In this work we have sought to examine the effect of HMG17 on transcription by RNA polymerase II by analysis of HMG17-containing chromatin that was prepared with a highly efficient chromatin assembly extract that yields regularly spaced nucleosomal arrays (Kamakaka et al. 1993; Bulger and Kadonaga 1994). We initially per- formed structural studies to characterize the incorporation of HMG17 into chromatin and then carried out the transcriptional analysis. The results of these experiments indicate that HMG17 is a chromatin-specific transcriptional coactivator that functions to increase the efficiency of initiation of transcription by RNA polymerase II.

\section{Results \\ HMG17 is efficiently incorporated into chromatin during assembly in vitro}

To investigate the effect of HMG17 on transcription by RNA polymerase II in the context of a chromatin template, it was necessary to assemble HMG17-containing chromatin in vitro. For the purposes of this study, however, it was not possible to obtain sufficient quantities of the native protein. Hence, we synthesized the calf thymus version of HMG17 in Escherichia coli and purified the protein to apparent homogeneity (Fig. 1). Amino-terminal amino acid sequencing and ion spray mass spectrometry indicated that the primary amino acid sequence of the recombinant HMG17 was identical to that of the native calf thymus protein (data not shown).

The purified HMG17 was then incorporated into chromatin by using a Drosophila chromatin assembly extract, termed the S-190, which assembles regularly spaced nucleosomal arrays efficiently (Kamakaka et al. 1993; Bulger and Kadonaga 1994). The S-190 extract appeared to be devoid of HMG17 (see Materials and methods), and thus, purified recombinant HMG17 was used in conjunction with the S-190 to generate HMG17-containing chromatin. Prior to carrying out the transcriptional analysis, it was essential to determine whether HMG17 was incorporated efficiently and properly into the chro-

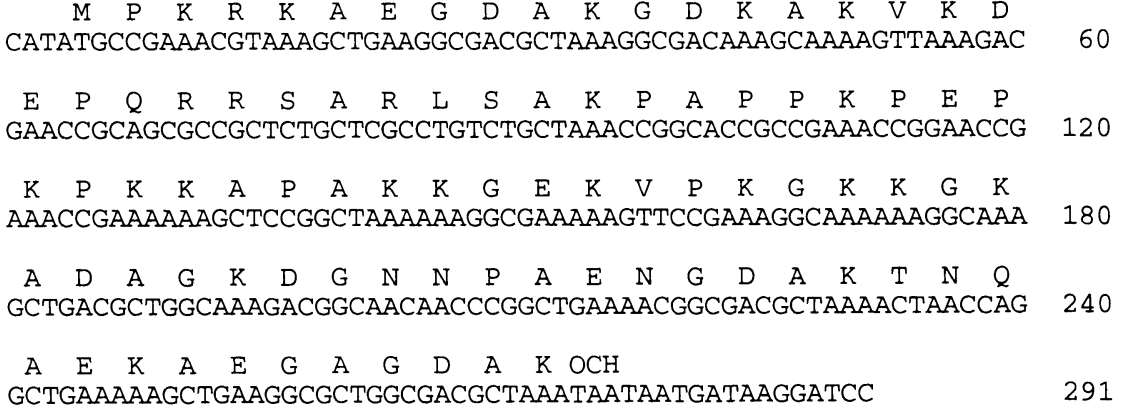

B

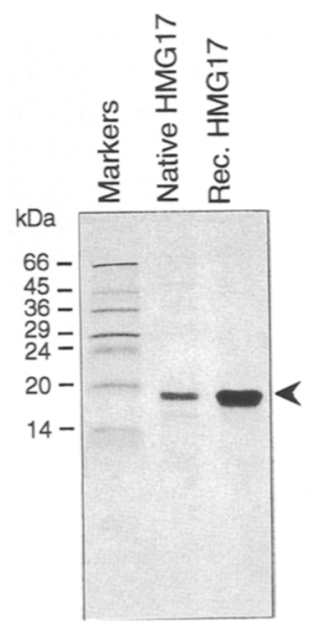

Figure 1. Synthesis and purification of recombinant HMG17. (A) DNA sequence of synthetic gene encoding calf thymus HMG17 that is optimized for expression in E. coli. (B) Purification of E. coli-synthesized HMG17. Purified, recombinant HMG17 and native HMG17 from calf thymus were analyzed by $15 \%$ polyacrylamide-SDS gel electrophoresis and staining with Coomassie blue. 
matin. We therefore performed a structural analysis of the HMG17-containing chromatin.

First, the newly assembled chromatin was subjected to micrococcal nuclease digestion analysis (Fig. 2A) (Noll and Kornberg 1977). Examination of the micrococcal nuclease digestion ladder obtained with the S-190 assembly system indicates that the presence of HMG17 does not affect the regularity of the nucleosomal spacing (Fig. 2A). The micrococcal nuclease digestion assay was also used to estimate the nucleosome repeat length (i.e., the center-to-center distance between adjacent nucleosomes). In the absence of HMG17 (Fig. 2A, 0 molecules HMG17/ $180 \mathrm{bp}$ ), a repeat length of $\sim 162 \mathrm{bp}$ was estimated from the sizes of the DNA fragments. This repeat length is consistent with the observation of 20 discrete nucleosomal bands (162 bp $\cong 3249$-bp plasmid/20 nucleosomes) in the micrococcal nuclease digestion ladder. In the presence of HMG17 (Fig. 2A, five molecules HMG17/180 $\mathrm{bp}$ ), a repeat length of $175 \mathrm{bp}$, which corresponds to $\sim 19$ nucleosomes per minichromosome, was estimated from the sizes of the DNA fragments. Therefore, the regularity of the nucleosomal spacing was unaffected by HMG17, but the nucleosome repeat length increased slightly if HMG17 was included during the chromatin assembly reactions.

The effect of HMG17 on the efficiency of chromatin assembly was then examined by DNA supercoiling analysis (Fig. 2B). The DNA supercoiling assay is based on the observation that the assembly of 1 nucleosome causes a change in the DNA linking number of $\sim-1$ (Germond et al. 1975; Simpson et al. 1985). In the experiment shown in Figure 2B, we examined the relative topological distribution of DNA that was obtained from chromatin assembled onto closed circular plasmid DNA with varying amounts of HMG17. These results revealed that the inclusion of five molecules of HMG17 per 180 bp DNA during chromatin assembly results in the assembly of $\sim 1$ less nucleosome onto the 3249-bp template, relative to the number of nucleosomes assembled in the absence of HMG17. This finding is consistent with the increase in the nucleosome repeat length observed in the micrococcal nuclease digestion assay (Fig. $2 \mathrm{~A}$ ), and the results therefore indicate that HMG17 does not affect the efficiency of chromatin assembly. This conclusion is supported further by analysis of the assembled chromatin by electron microscopy, wherein fully assembled chromatin was observed when the reactions were carried out in either the presence or the absence of HMG17 (Fig. 2C).

Next, the incorporation of HMG17 into the assembled chromatin was examined by native nucleoprotein gel electrophoresis (Fig. 2D). In this assay, the specific binding of either HMG14 or HMG17 to core particles results in a reduction in the mobility of core particles during native gel electrophoresis (Albright et al. 1980; Mardian et al. 1980; Sandeen et al. 1980; Crippa et al. 1992, 1993; Alfonso et al. 1994). Chromatin was assembled in the presence or absence of HMG17, purified by sucrose gradient sedimentation, digested extensively (to core particles) with micrococcal nuclease, and then subjected to electrophoresis on a nondenaturing polyacrylamide gel. As shown in Figure 2D, the inclusion of 2.5 molecules of HMG17 per 180 bp of DNA during chromatin assembly resulted in the nearly quantitative binding of 2 molecules of HMG 17 per core particle. It thus appears that the interaction of the purified, recombinant HMG17 with chromatin is identical to that of the native protein. In addition, the absence of a gel-shifted species when exogenous HMG 17 was omitted from the assembly reactions further confirmed that the S-190 assembly extract does not contain a significant amount of an HMG14/17-related factor.

Finally, it has been suggested that HMG14/17 might displace an $\mathrm{H} 2 \mathrm{~A}-\mathrm{H} 2 \mathrm{~B}$ dimer in the nucleosome (see, e.g., Baer and Rhodes 1983; González and Palacián 1990; Tremethick 1994), and to address this point, we examined the protein composition of chromatin that was assembled in either the presence or the absence of HMG17 by SDS-PAGE and staining with Coomassie brilliant blue (Fig. 2E). This experiment revealed that there was no apparent depletion of $\mathrm{H} 2 \mathrm{~A}-\mathrm{H} 2 \mathrm{~B}$ upon incorporation of HMG17 into the chromatin, which is consistent with the results of previous studies in which the protein composition of HMG17-containing chromatin was examined (see, e.g., Albright et al. 1980; Shick et al. 1985; Crippa et al. 1993).

Hence, the structural data indicate that the purified, recombinant $\mathrm{HMG} 17$ induces a slight increase in the nucleosome repeat length (Fig. 2A), does not inhibit the highly efficient chromatin assembly process (Fig. 2B,C), and is quantitatively incorporated into chromatin in a physiological manner (Fig. 2D) with the full complement of core histones (Fig. 2E).

\section{HMG17 is a chromatin-specific transcriptional coactivator}

To analyze the transcriptional properties of the HMG17containing chromatin, we employed the synthetic activator GAL4-VP16 along with basal transcription factors derived from either HeLa (human) cells or Drosophila embryos. GAL4-VP16 consists of the amino-terminal 147 amino acid residues /comprising the DNA-binding domain) of the yeast GAL4 protein fused to a fragment of the herpesvirus VP16 protein, which contains a potent transcriptional activation region (see, e.g., Sadowski et al. 1988; Chasman et al. 1989). GAL4-VP16 has been used widely in the study of eukaryotic transcriptional regulation and therefore serves as a useful reference or standard for a model activator.

Chromatin templates were assembled with varying amounts of HMG17 in the presence or the absence of GAL4-VP16, and then parallel transcription reactions were carried out with either a HeLa extract (Fig. 3A) or a Drosophila embryo extract (Fig. 3B), both of which were prepared by salt extraction of nuclei by conventional methods (Dignam et al. 1983). In reactions performed with the HeLa extract, the incorporation of HMG 17 into the chromatin templates resulted in stimulation of GAL4-VP16-activated transcription. The highest 
Molecules of HMG17/180 bp DNA Added during Chromatin Assembly

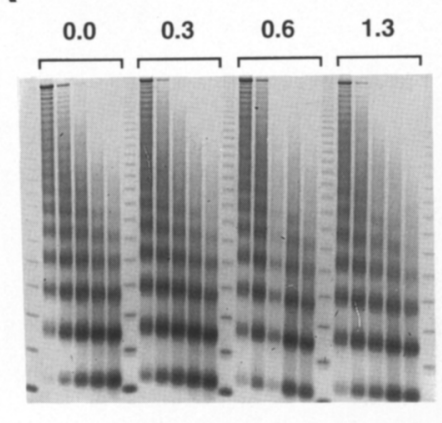

C

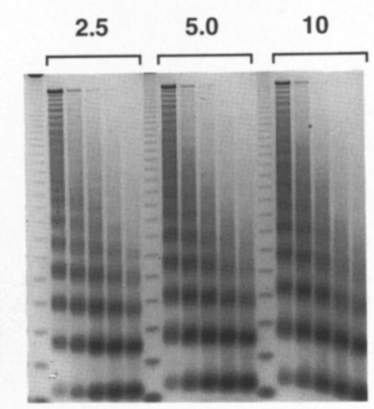

D

O HMG17 per 180 bp 2.5 HMG17
per per
$180 \mathrm{bp}$ 5 HMG17 per
180 bp
HMG17 Incorporated during Chromatin Assembly
(molecules/180 bp DNA)

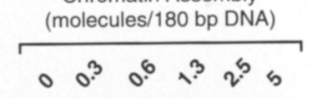

B
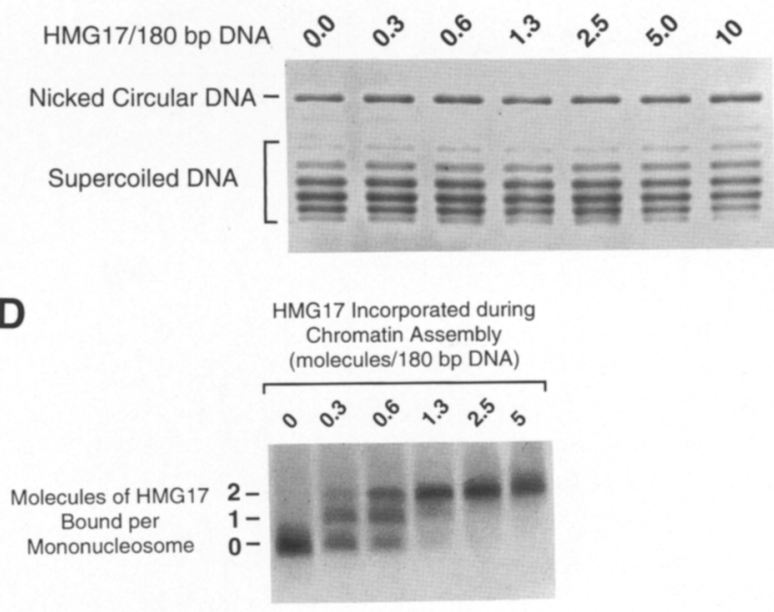

E

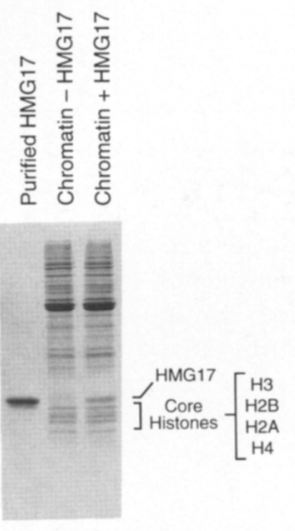

Figure 2. HMG17 is efficiently incorporated into chromatin during assembly in vitro. $(A)$ HMG17 increases the nucleosome repeat length but not the regularity of nucleosomal spacing when present during chromatin assembly. Chromatin was assembled onto $\mathrm{pG}_{5} \mathrm{E} 4 \mathrm{~T}$ plasmid DNA with the indicated amounts of purified HMG17 and then subjected to micrococcal nuclease digestion analysis. The molecular mass standards are the 123-bp ladder (GIBCO-BRL). (B) HMG17 does not affect the efficiency of chromatin assembly, as determined by DNA supercoiling analysis. Chromatin was assembled onto pG $_{5}$ E4T plasmid DNA with the S-190 extract /which contains endogenous topoisomerase I) and the indicated amounts of purified HMG17. The resulting templates were deproteinized and subjected to $2 \%$ agarose gel electrophoresis in the presence of $2 \mu \mathrm{M}$ chloroquine. The DNA was visualized by fluorescence of the DNA after staining with ethidium bromide. (C) HMG17 does not affect the efficiency of chromatin assembly, as determined by electron microscopy. Chromatin was assembled onto $\mathrm{pG}_{5} \mathrm{E} 4 \mathrm{Kr}$ plasmid DNA (9.8 kbp; Kamakaka et al. 1993) and analyzed by electron microscopy, as described previously (Thoma et al. 1979; Kamakaka et al. 1993). (D) HMG17 is incorporated into chromatin, as determined by native nucleoprotein gel electrophoresis of core particles. Chromatin was assembled onto plasmid DNA with the indicated amounts of HMG17, purified by sucrose gradient sedimentation, and then digested extensively with micrococcal nuclease. The resulting nucleosomal core particles were subjected to electrophoresis in a $5 \%$ nondenaturing-polyacrylamide gel. The core particles were visualized by fluorescence of the DNA after staining with ethidium bromide. The positions of core particles containing zero, one, or two molecules of HMG17 are denoted (left). $(E)$ HMG17 is incorporated into chromatin, as determined by SDS-PAGE. Chromatin was assembled onto plasmid DNA in the presence of either 0 or 10 molecules of HMG17 per 180 bp of DNA (similar results were obtained with 5 molecules of HMG17 per $180 \mathrm{bp}$ of DNA; data not shown), purified by sucrose gradient sedimentation, and then subjected to $15 \%$ SDS-PAGE. The proteins were visualized by staining with Coomassie blue.

amounts of transcriptional activity were observed when GAL4-VP16 was added along with HMG17 prior to the assembly of chromatin, where a 7 - to 40 -fold increase in transcription by HMG17 was typically observed /at 10 molecules of HMG17 per 180 bp of DNA during assembly). With the Drosophila extract, the results were similar to those obtained with the HeLa extract. Hence, with extracts derived from either HeLa cells or Drosophila 


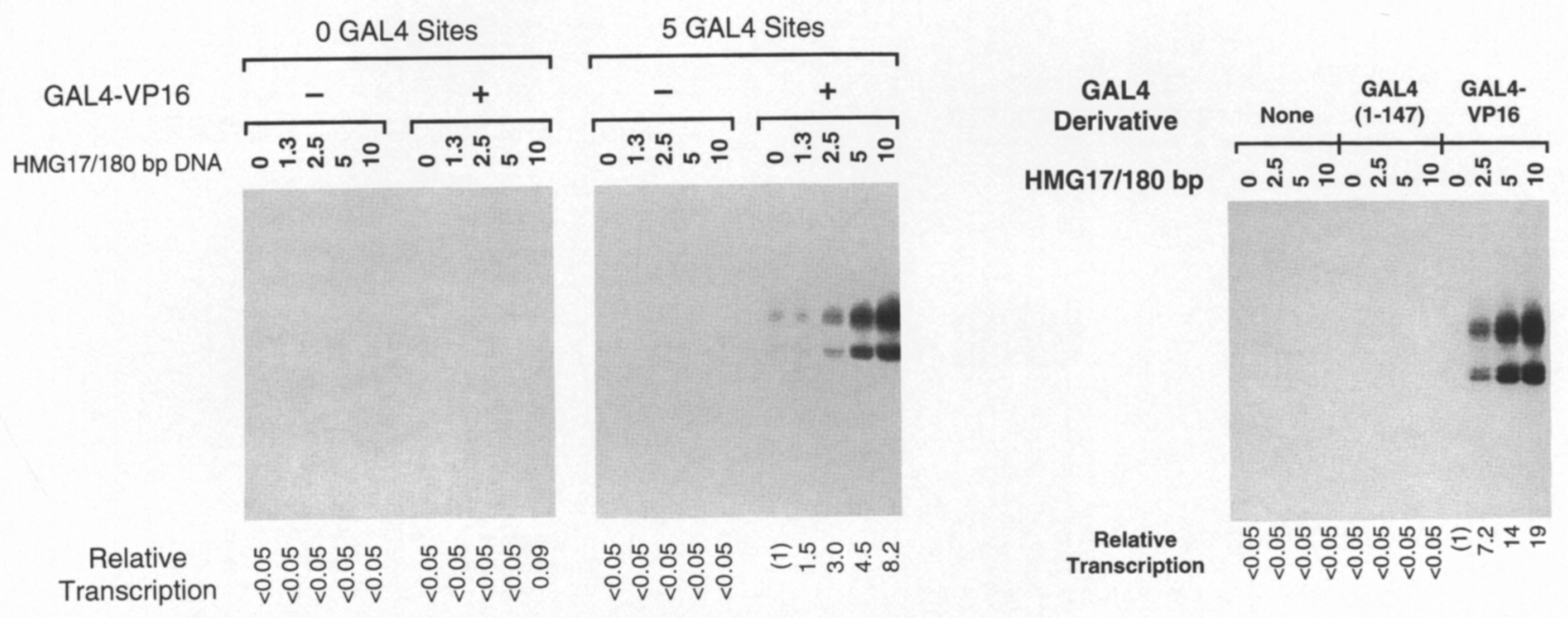

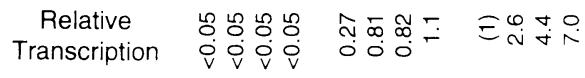

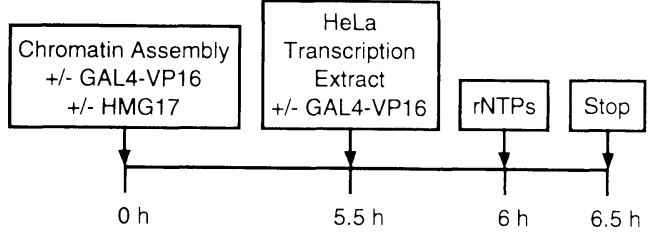
Transcription

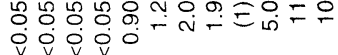

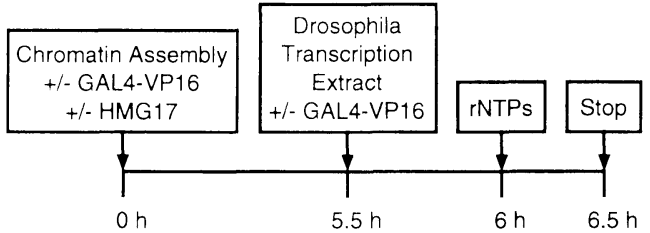

Figure 3. HMG 17 is a transcriptional coactivator with chromatin templates. Chromatin was assembled onto $\mathrm{pG}_{5} \mathrm{E} 4 \mathrm{~T}$ (which contains five GAL4-binding sites) plasmid DNA with the indicated amounts of HMG17. As depicted, GAL4-VP16 was added either before or after chromatin assembly. Transcription reactions were carried out as outlined in the reaction schemes under the autoradiographs. The resulting transcripts were characterized by primer extension analysis, and the relative amounts of transcription are shown at the bottom. (A) HMG17 potentiates transcriptional activation by GAL4-VP16 with a HeLa (human) nuclear extract. $(B)$ HMG17 potentiates transcriptional activation by GAL4-VP16 with a Drosophila nuclear extract.

embryos, the incorporation of HMG17 into chromatin augments GAL4-VP16-activated transcription. In this capacity, we refer to HMG 17 as a transcriptional coactivator.

We then used the HeLa extracts to examine the characteristics of HMG17-mediated transcriptional activation as follows. First, to see whether DNA binding by GAL4-VP16 is required for potentiation of transcription by HMG17, we carried out transcription reactions with templates that contained either five or zero GAL4-binding sites (Fig. 4A). This experiment indicated that the stimulation of GAL4-VP16-activated transcription by HMG17 was dependent on the presence of GAL4-binding sites in the promoter. Second, to test whether the VP16 activation domain is essential for the augmentation of transcription by $\mathrm{HMG} 17$, we performed reactions with either GAL4-VP16 or GAL4(1-147), which is identical to GAL4-VP16 except that it lacks the VP16 activation domain (Fig. 4B). This experiment revealed that HMG 17 was able to function as a coactivator with GAL4-VP16 but had no effect with GAL4(1-147), which was bound to the DNA (as determined by DNase I footprinting; data not shown) but was transcriptionally in- active. Hence, HMG17-mediated activation of transcription requires the binding of the GAL4-VP16 to the template, but DNA binding by GAL4(1-147) is not sufficient for this transcriptional potentiation.

To determine whether a chromatin template is required for HMG 17 coactivator function, we examined the transcriptional properties of nonchromatin templates. As shown in Figure 5A, when mock-assembled chromatin was prepared by omission of exogenous core histones from the assembly reactions, HMG17 did not stimulate transcription from the resulting nonchromatin templates. We also examined the effect of HMG17 on transcription of naked DNA templates by basal transcription factors purified to $>90 \%$ homogeneity (Fig. 5B). In this experiment, HMG17 repressed transcription mildly, which demonstrates that HMG17 does not stimulate transcription nonspecifically by RNA polymerase II. Hence, these results indicate that the stimulation of GAL4-VP16-activated transcription by HMG17 is chromatin-dependent, which suggests that the specific binding of HMGl7 to nucleosomal DNA, as characterized previously (Fig. 2D; Albright et al. 1980; Mardian et al. 1980; Sandeen et al. 1980; Crippa et al. 1992, 1993; Al- 

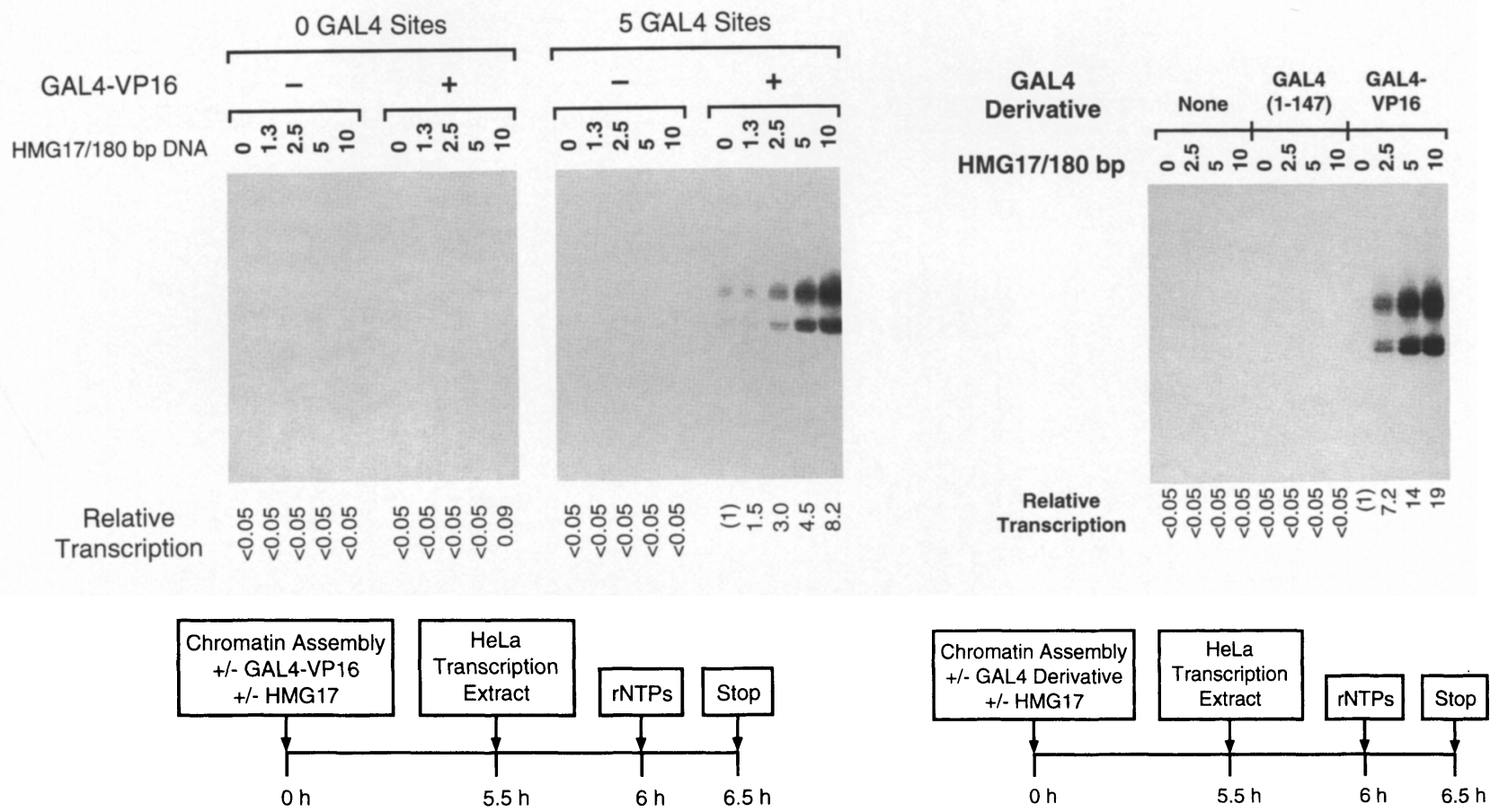

Figure 4. Transcriptional activation by HMG17 requires GAL4-binding sites and the VP16 activation domain. Chromatin was assembled onto either $\mathrm{pG}_{5} \mathrm{E} 4 \mathrm{~T}$ (which contains five GAL4-binding sites) or $\mathrm{pG}_{0} \mathrm{E} 4 \mathrm{~T}$ (which does not contain GAL4-binding sites) plasmid DNA with the indicated amounts of HMG17. As depicted, either GAL4-VP16 or GAL4(1-147) was added before chromatin assembly. Transcription reactions were carried out as outlined in the reaction schemes under the autoradiographs. $(A)$ Potentiation of GAL4-VP16-mediated transcriptional activation by HMG17 is dependent on the presence of GAL4-binding sites in the promoter. (B) Binding of GAL4(1-147) to the template is not sufficient for transcriptional potentiation by HMG17. GAL4(1-147) contains the amino-terminal 147 amino acid residues of the yeast GAL4 protein and is identical to GAL4-VP16, except that it does not contain the transcriptional activation domain derived from the herpesvirus VP16 protein.

fonso et al. 1994), is an essential requirement for its function as a transcriptional coactivator.

\section{HMG17 must be incorporated into chromatin during assembly for coactivator function}

To investigate the nature of the incorporation of HMG17 into chromatin that is necessary for its function as a coactivator, we examined the transcriptional properties of chromatin templates to which HMG17 had been added before and/or after chromatin assembly (Fig. 6). This experiment revealed that HMG17 did not stimulate transcription when it was added to the templates after assembly, which is in contrast to the activation that is observed when HMG17 is incorporated into chromatin during assembly. For instance, the amount of transcription obtained upon addition of five molecules of HMG17/180 bp before assembly (29-fold stimulation by HMG17) was significantly higher than that observed upon addition of five molecules of HMG17/180 bp after assembly (1.5-fold stimulation by HMG17). Hence, HMG17 must be incorporated into chromatin during assembly to function as a transcriptional coactivator.
Moreover, as a parenthetical note, because the addition of HMG17 after chromatin assembly has little effect at 5 molecules of $\mathrm{HMG} 17 / 180 \mathrm{bp}$ and a mild repressive effect at high levels of factor ( 80 molecules of HMG17/180 bp), even if moderate amounts of contaminating HMG17 were present in the HeLa transcription extracts /which have been depleted of HMG 17 by precipitation of the basal factors with ammonium sulfate; see Materials and methods|, the results of these experiments would not have been affected significantly.

\section{HMG17 increases the efficiency of transcription initiation but not the extent of elongation}

To examine the step in the transcription process that is affected by the incorporation of HMG17 into chromatin, we carried out transcription reactions in either the presence or the absence of Sarkosyl, an anionic detergent that inhibits assembly of the preinitiation complex under conditions where transcription elongation is unaffected (Hawley and Roeder 1985, 1987; Kadonaga 1990). Through the use of transcriptional inhibitors such as Sarkosyl, it has been possible to subdivide the transcription 
Paranjape et al.

\section{A}

B
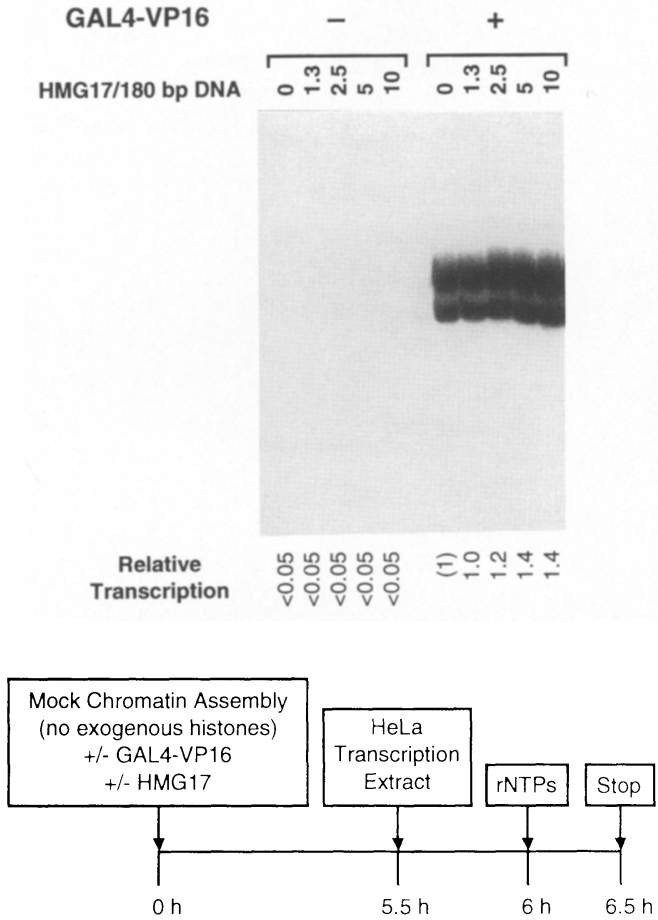

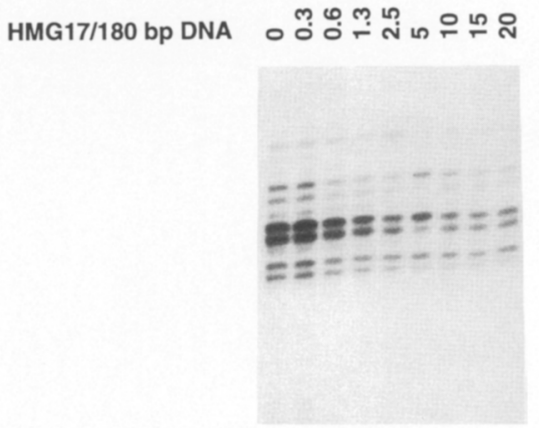

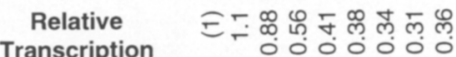

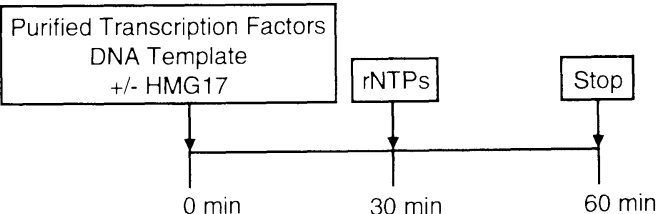

Figure 5. HMG17 is a chromatin-specific transcriptional coactivator. $(A)$ HMG 17 does not potentiate transcriptional activation in the absence of chromatin assembly. Mock assembly reactions were carried out with pG ${ }_{5}$ E4T plasmid DNA in the absence of exogenous core histones, which are required for assembly of chromatin with the Drosophila S-190 extract (Kamakaka et al. 1993; Bulger and Kadonaga 1994). HMG17 and GAL4-VP16 were included in the mock assembly reactions, as indicated. (B) HMG17 mildly represses transcription by purified basal factors with naked DNA templates. The indicated amounts of HMG17 were preincubated with pKr template DNA for $15 \mathrm{~min}$. Transcription reactions were then carried out with TBP, TFIIB, TFIIE, TFIIF, and RNA polymerase II, each of which was purified to $>90 \%$ homogeneity, as described previously (Tyree et al. 1993).

reaction into three steps: (1) assembly of the preinitiation complex, which can occur in the absence of the ribonucleoside 5 '-triphosphates (rNTPs) and is inhibited by Sarkosyl; (2) the rapid conversion of the preinitiation complex into the elongating polymerase; and (3) transcription elongation, which is not inhibited by Sarkosyl.

We therefore carried out single-round transcription reactions with chromatin templates that were assembled with GAL4-VP16 in either the presence or the absence of HMG17 (Fig. 7). Transcription preinitiation complexes were formed by the incubation of HeLa extract with preassembled chromatin templates, and transcription was initiated by the addition of rNTPs. Then, to inhibit reinitiation but not elongation, Sarkosyl was added to the reaction medium /containing the elongating polymerase) $10 \mathrm{sec}$ after the rNTPs. These experiments revealed that the incorporation of HMG 17 into chromatin results in an increase in the efficiency of transcription in a single round of transcription. Moreover, the magnitude of activation by HMG17 in a single round of transcription was similar to that observed in the absence of Sarkosyl, which suggests that the transcriptional en- hancement by HMG17 occurs primarily at the level of initiation.

We also examined the effect of HMG17 on the extent of transcriptional elongation (Fig. 8). First, we compared the effect of HMG17 on the synthesis of shorter transcripts (100 nucleotides) versus longer transcripts (354 nucleotides) and observed the same amount of activation in both instances (Fig. 8A). We then mapped the 3 ' ends of the transcripts that were synthesized from the chromatin templates (Fig. 8B). This experiment revealed that the synthesis of transcripts ranging in length from $\sim 60$ nucleotides to $>500$ nucleotides were stimulated to a comparable degree by the incorporation of HMGl 7 into the chromatin. It therefore appears that HMG17 increases the efficiency of transcription initiation but not the extent of transcriptional elongation from chromatin templates.

\section{Discussion}

In this study we have found that HMG17 is a chromatinspecific transcriptional coactivator. HMG 17 was termed 

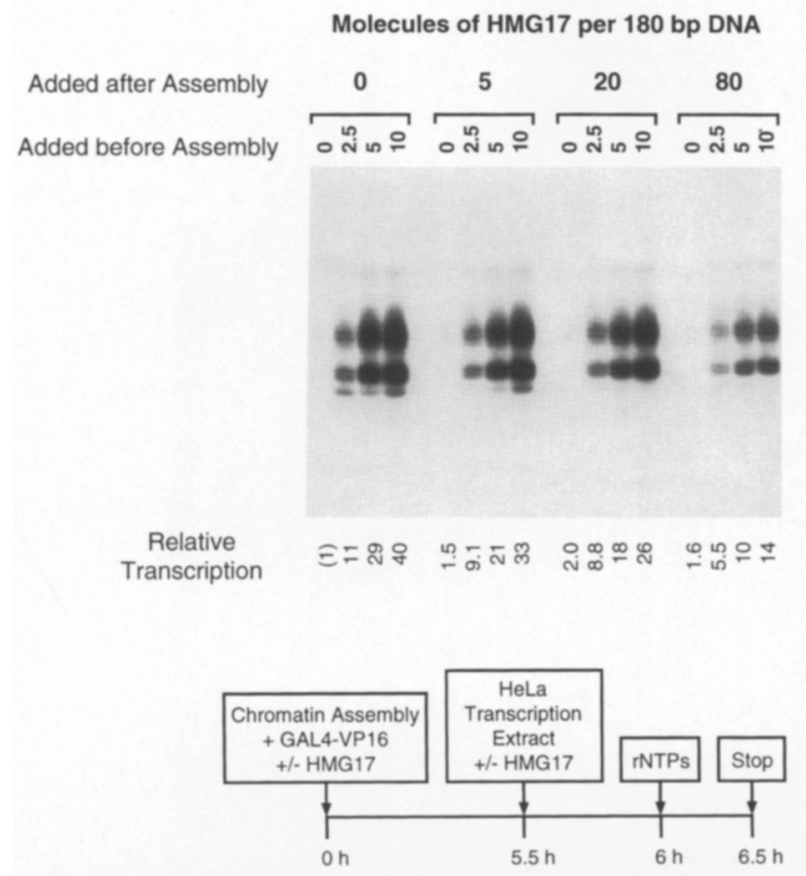

Figure 6. HMG17 must be present during chromatin assembly to function as a coactivator. Chromatin was assembled onto $\mathrm{pG}_{5} \mathrm{E} 4 \mathrm{~T}$ plasmid DNA in the presence of GAL4-VP16. Purified HMG17 was added before and/or after assembly, as indicated.

a coactivator because stimulation of transcription by HMG17 to high levels occurred only in conjunction with the GAL4-VP16 activator (Fig. 3). In the presence of GAL4-VP16, the incorporation of HMG17 into the chromatin resulted in a 7- to 40-fold activation of transcription, whereas in the absence of GAL4-VP16 or with a GAL4 derivative [GAL4(1-147)] lacking the VP16 activation domain, the amount of transcription observed upon incorporation of HMG17 into chromatin was $<0.5 \%$ of that observed in the presence of GAL4-VP16 under otherwise identical conditions. Moreover, the absolute amount of GAL4-VP16-activated transcription observed with the chromatin templates in the presence of HMG17 was $\sim 30 \%-40 \%$ of that observed with histone-free templates (data not shown). Hence, the transcriptional potential of HMG17-containing chromatin is similar to that of unrepressed histone-free DNA.

The action of HMG17 was termed chromatin-specific because it stimulates transcription with chromatin but not with non-nucleosomal templates (Fig. 5). This specificity of HMG17 for chromatin templates is consistent with its higher affinity for nucleosomes relative to naked DNA (Sandeen et al. 1980) and suggests that binding of HMG17 to its specific binding sites on nucleosomal cores is required for its function as a coactivator. In addition, HMG17-mediated activation was observed when HMG17 was present during chromatin assembly but not when HMG17 was added to the chromatin after assembly (Fig. 6). This finding indicates that the interaction of HMG17 with chromatin is different when HMG17 is included during chromatin assembly than when it is added after assembly. The highest levels of transcriptional activation were observed when both GAL4-VP16 and HMG17 were present during chromatin assembly (Figs. 3 and 6), and it is possible that there are functional interactions between HMG17 and GAL4-VP16. A precedent for such HMG14/17 transcription factor interactions is the finding that thyroid hormone receptor binds to an HMG14/17-related protein in a thyroid hormonedependent manner (Lee et al. 1995). Finally, HMG17 increases the efficiency of transcription initiation (Fig. 7) but not the extent of transcriptional elongation (Fig. 8). These results suggest a model for HMG17 function wherein a potentiated transcriptional state is achieved upon binding of a transcriptional activator (such as GAL4-VP16) and HMG14/17 to the template during DNA replication and chromatin assembly.

\section{Properties of HMG17-containing chromatin}

In this study we have devoted considerable effort toward the structural characterization of chromatin that was assembled with HMG17 because it was essential to determine whether the HMG17 was incorporated properly

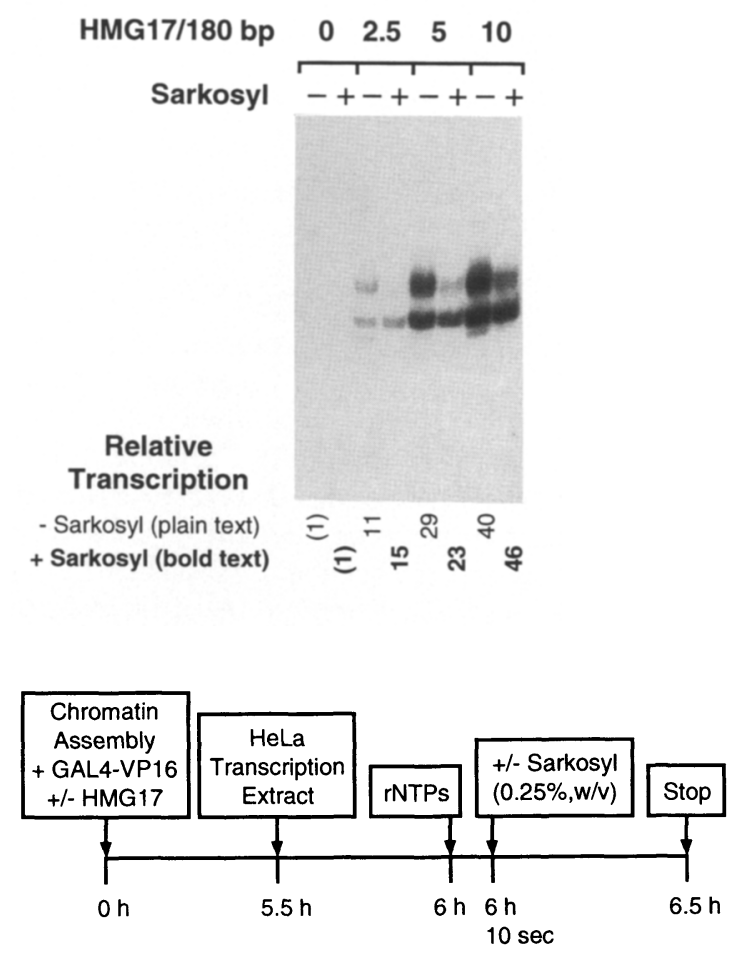

Figure 7. HMG17 increases the efficiency of transcription initiation. Chromatin was assembled onto $\mathrm{pG}_{5} \mathrm{E} 4 \mathrm{~T}$ plasmid DNA in the presence of GAL4-VP16. HMG17 was included in the assembly reactions as indicated. Where noted, transcription reactions were limited to a single round by inhibition of transcription reinitiation by the anionic detergent Sarkosyl (Hawley and Roeder 1985, 1987; Kadonaga 1990). There was no detectable transcription in control reactions in which the rNTPs were omitted (data not shown). 
A

Figure 8. HMG17 does not affect the extent of transcriptional elongation. $(A)$ Primer extension analysis. Chromatin was assembled onto $\mathrm{pG}_{5} \mathrm{E} 4 \mathrm{~T}$ plasmid DNA in the presence of GAL4-VP16. HMG17 was included in the assembly reactions as indicated. Transcription reactions were then carried out with a HeLa nuclear extract. The resulting RNA was subjected to primer extension analysis by using oligonucleotide primers that yielded reverse transcription products of either 100 or 354 nucleotides. (B) S1 nuclease mapping of 3 ' ends of in vitro-transcribed RNA. Chromatin was assembled onto pGAL-TATA-MG template DNA, which consists of a promoter containing three GAL4-binding sites immediately upstream of the TATA consensus sequence (of the adenovirus major late promoter) and chimeric downstream sequences derived from the human c-myc and $\beta$-globin genes (Krumm et al. 1995). Where indicated, GAL4-VP16 and/or HMG17 (7.5 molecules/ $180 \mathrm{bp}$ ) were included in the chromatin assembly reactions. Transcription reactions were carried out with a HeLa nuclear extract, and the resulting RNA was subjected to $3^{\prime}$ end mapping by hybridization to a $3^{\prime}$-end-labeled probe (corresponding to sequences from +15 to +767 relative to the RNA start site) followed by digestion with $\mathrm{S} 1$ nuclease.

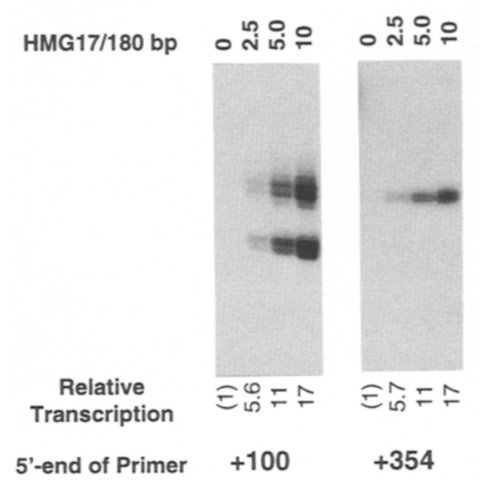

B

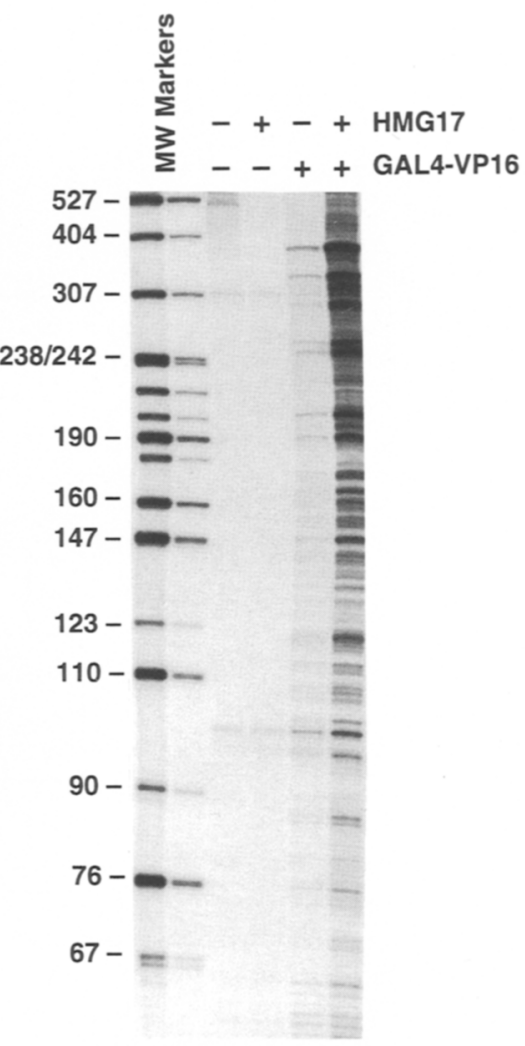

into the chromatin. These experiments included micrococcal nuclease digestion analysis, DNA supercoiling assays, nondenaturing gel electrophoresis of core particles, electron microscopy, and SDS-PAGE (Fig. 2). These experiments indicated that HMG17 was efficiently incorporated into chromatin during assembly in vitro; HMG17-containing chromatin contained fully assembled nucleosomal arrays and was not depleted of histones $\mathrm{H} 2 \mathrm{~A}-\mathrm{H} 2 \mathrm{~B}$; and binding of HMG17 to chromatin resulted in a slight increase in the nucleosome repeat length (from $162 \mathrm{bp}$ in the absence of HMG17 to $175 \mathrm{bp}$ at five molecules of HMG17 per 180 bp of DNA during assembly). [The increase in the repeat length in the presence of HMG17 might be related to the finding that phosphorylated HMG14/17 can, under certain conditions, increase the repeat length of reconstituted chromatin from 145 to $\sim 160-165$ bp (Drew 1993; Tremethick and Drew 1993), but it is difficult to compare the data because of the significant differences in the chromatin reconstitution systems used in the other work. Note also that our observation of the increase in the repeat length in the presence of HMG17 is in contrast to the interpretation of the micrococcal nuclease digestion data of previous studies, wherein it was concluded that incorporation of HMG14/17 into chromatin does not affect the repeat length /Crippa et al. 1993; Trieschmann et al. 1995). We suggest, however, that the differences may be in the interpretation of the data because in the earlier work, the micrococcal nuclease digestion ladders con- tained only three or four bands, which led to difficulty in the determination of the nucleosomal repeat lengths.] Hence, the structural analysis revealed that HMG17 was efficiently and properly incorporated into chromatin that was assembled with double-stranded, circular plasmid DNA, and these data thus indicate that the HMG17mediated transcriptional activation was not attributable to a general inhibition of chromatin assembly.

In other work, a Xenopus egg extract was used to prepare HMG17-containing chromatin for the analysis of the effect of HMG17 on transcription by RNA polymerase III (Crippa et al. 1993; Trieschmann et al. 1995). In those experiments, chromatin was generated from a single-stranded-circular DNA template by a coupled DNA replication (complementary strand synthesis)-chromatin assembly process that was carried out in the absence of $\mathrm{Mg}$ (II)-ATP. [Although it was noted (Crippa et al. 1993) that chromatin prepared in the absence of $\mathrm{Mg}(\mathrm{II})$ ATP possessed the full complement of core histones, it has also been shown that chromatin assembled in the absence of $\mathrm{Mg}$ (II)-ATP under apparently identical conditions was deficient in histones $\mathrm{H} 2 \mathrm{~A}$ and $\mathrm{H} 2 \mathrm{~B}$ (Almouzni et al. 1991।. In addition, chromatin assembled in the absence of $\mathrm{Mg}(\mathrm{II})-\mathrm{ATP}$ exhibited increased accessibility to digestion by micrococcal nuclease (Crippa et al. 1993; Trieschmann et al. 1995). It is thus likely that chromatin assembled in the absence of $\mathrm{Mg}(\mathrm{II})-\mathrm{ATP}$ is assembled less efficiently and/or folded less compactly.] Under those conditions, it was necessary to include 100 mole- 
cules of HMG17 per $200 \mathrm{bp}$ of DNA to assemble chromatin that contained two molecules of HMG17 per nucleosome (as determined by the native nucleoprotein gel shift assay, similar to that shown in Fig. 2D|. The incorporation of HMG17 then resulted in a severalfold increase in transcription by RNA polymerase III when the chromatin was assembled in the absence of $\mathrm{Mg}(\mathrm{II})-\mathrm{ATP}$. When $\mathrm{Mg}$ (II)-ATP was included during chromatin assembly, however, no effect of HMG17 was observed. In addition, HMG17 stimulated RNA polymerase III transcription when it was included during, but not after chromatin assembly. Further experiments then led to the suggestion that HMG14/17 activate transcription by disruption of higher order chromatin structure (Trieschmann et al. 1995).

There are many differences among the results observed in other studies of HMG14/17 (Crippa et al. 1993; Trieschmann et al. 1995) and those of this work. First, we have found that HMG17 functions as a transcriptional coactivator, and in the absence of the GAL4-VP16 activator protein, HMG17 does not stimulate basal transcription by RNA polymerase II. In contrast, in the other studies, HMG17 stimulated transcription of both the $5 \mathrm{~S}$ RNA gene and satellite I chromatin (Crippa et al. 1993; Trieschmann et al. 1995). Second, with the Xenopus extract-assembled chromatin used in the other work, a ratio of 20-60 molecules of HMG17 per 200 bp of DNA was required to see a stimulation of transcription by HMG17, whereas in this study, we observed transcriptional activation by HMG17 at $2.5-5$ molecules of HMG17 per $180 \mathrm{bp}$ of DNA. Third, single-round transcription experiments with the Xenopus system revealed that HMG17 did not significantly (1.4-fold) increase the efficiency of transcription initiation by RNA polymerase III (Trieschmann et al. 1995), whereas we have found that the stimulation of transcription by HMG17 occurs by increasing the efficiency of transcription initiation by RNA polymerase II.

In addition to the topics discussed above, there are other differences in the conclusions of previous work on HMG14/17 and those of this study. To minimize potential confusion regarding the function of HMG17, it would probably be most useful to evaluate the data independently while also considering the fundamental distinctions in the experimental methodology and transcription systems. A particularly critical issue appears to be the structure of the chromatin that is assembled in the absence of $\mathrm{Mg}$ (II)-ATP. In the earlier work (Crippa et al. 1993), transcriptional activation by HMG17 was not observed when $\mathrm{Mg}$ (II)-ATP was present during chromatin assembly. HMG14/17-mediated stimulation of transcription by RNA polymerase III occurred only when chromatin assembly was performed in the absence of $\mathrm{Mg}$ (II-ATP, yet the integrity of such chromatin is uncertain because of the well-characterized requirement for $\mathrm{Mg}$ (II)-ATP for efficient assembly of regularly spaced nucleosomes with the Xenopus assembly systems (Glikin et al. 1984; Almouzni and Méchali 1988; Almouzni et al. 1991). In comparison, in our work, chromatin was assembled efficienctly in the presence of physiological concentrations $(\sim 3 \mathrm{~mm})$ of $\mathrm{Mg}$ (II)-ATP [note that $\mathrm{Mg}(\mathrm{II})-\mathrm{ATP}$ is required for chromatin assembly by the Drosophila S-190 extract (Kamakaka et al. 1993)].

\section{Does HMG17 stimulate transcription initiation and/or elongation?}

The single-round transcription experiments with Sarkosyl (which inhibited reinitiation, but not elongation) (Fig. 7), along with the analyses of transcriptional elongation (Fig. 8), had shown that the incorporation of HMG17 into chromatin increases the efficiency of transcription initiation but not the extent of elongation. These results are in apparent contradiction to the previous finding that HMG14 stimulates transcriptional elongation but not transcription initiation with the SV40 late promoter in isolated SV40 minichromosomes (Ding et al. 1994). In that work it was also found that the addition of purified HMG14 to minichromosomes resulted in a severalfold stimulation of transcription, which is in contrast to the results of Crippa et al. (1993) and this work (Fig. 6), where HMG17 did not stimulate transcription when it was added to preassembled chromatin. It is possible that these discrepancies are attributable, in part, to the use of HMG14 versus HMG17 as well as fully assembled chromatin templates versus SV40 minichromosomes, which are transcriptionally active templates with a nucleosome-free enhancer region. Thus, the SV40 minichromosomes are active chromatin, whereas the nucleosomal templates assembled in vitro may represent either active or inactive chromatin, as determined by the presence or the absence of activator proteins (such as GAL4VP16) and coactivators (such as HMG17).

\section{Mechanism of transcriptional activation by HMG17}

How might HMG17 function as a chromatin-specific coactivator? Two possible models are as follows: (1) HMG17 may participate directly in the transcription process, or (2) HMG17, perhaps in conjunction with sequence-specific DNA-binding factors, may render the chromatin more accessible to the transcriptional machinery. The former model seems unlikely for a few reasons. First, HMG17 has no effect (or a mild repressive effect) on basal or activated transcription with nonchromatin templates (Fig. 5). Second, the abundance of HMG17 (roughly one molecule per 400 bp of DNA; Kuehl et al. 1984) is comparable to that of integral components of chromatin, such as histones, and much higher than that of transcription factors. Third, LexA-HMG14 and LexA-HMG17 fusion proteins were not able to function as transcriptional activators in yeast cells (Landsman and Bustin 1991). We thus favor the latter model, wherein HMG17 increases the ability of the basal transcriptional machinery to transcribe the repressed chromatin template. Given the requirement for both HMG17 and GAL4-VP16 to be present during chromatin assembly to attain full activation, it is further conceivable that specific interactions among HMG17, GAL4-VP16, and 
the transcriptional machinery are required to achieve high levels of transcription.

In this work we have found that the magnitude of transcriptional potentiation by HMG17 was similar when the transcription reactions were carried out with high salt $(0.42 \mathrm{~m} \mathrm{KCl})$ nuclear extracts derived from either HeLa cells or Drosophila embryos (Fig. 3). In further studies, we have also performed reactions with a low salt $(0.1 \mathrm{~m} \mathrm{KCl})$ Drosophila nuclear extract, termed the soluble nuclear fraction (Kamakaka et al. 1991; Kamakaka and Kadonaga 1994), and observed higher transcriptional activity in the absence of HMG17 and a smaller stimulatory effect on inclusion of HMG17 (typically, a two- to fourfold increase at 10 molecules HMG17/180 bp/ relative to that observed with the high salt nuclear extracts (data not shown). The basis for this difference is not yet known, but the results suggest that there are factors (which are differentially extracted from nuclei at high vs. low salt) in addition to the basal transcriptional machinery and the HMG17-containing nucleosomal template that are involved in transcriptional potentiation by HMG17.

Finally, in this context, it is pertinent to address an issue regarding the stoichiometry of HMGl7 binding to chromatin. We have found that the magnitude of transcriptional potentiation by HMG17 at either 5 or 10 molecules per $180 \mathrm{bp}$ (added during assembly) was greater than that by HMG17 at 2.5 molecules per $180 \mathrm{bp}$, a concentration at which 2 molecules of HMG17 bound per core particle were observed in the native nucleoprotein gel shift assay (Fig. 2D). On the basis of these results, we suggest that the templates assembled with the higher amounts $(5$ or 10 molecules/180 bp) of HMG17 might contain $>2$ molecules of HMG17 bound per nucleosome. It is possible that there are HMG17-binding sites in nucleosomal arrays that are not detected, or weakly detected, after digestion of chromatin into core particles, as in the gel shift assay (Fig. 2D). Consistent with this notion, three to six molecules of HMG 14/17 per core particle can be seen in the gel shift assay under some electrophoretic conditions (Mardian et al. 1980; Paton et al. 1983; this study, data not shown). Hence, in the analysis of the role of HMG14/17 in gene activation, it may be useful to consider that potentiated or active chromatin may contain, at least transiently, greater than two molecules per nucleosome.

\section{Role of HMG14/17 in the regulation of gene expression}

How might HMG17, which is present at an estimated abundance of $\sim 0.5$ molecule per nucleosome (Kuehl et al. 1984), participate in transcriptional activation in vivo if 2 or more molecules per nucleosome are required for its function? A possible mechanism by which HMG14/ 17 could be localized to active or potentiated genes is by interaction with transcription factors. For instance, as mentioned earlier, a direct interaction between the thyroid hormone receptor and an HMG14/17-related protein has been identified (Lee et al. 1995). It is also conceivable that HMG14/17 proteins are excluded from transcriptionally inactive chromatin, such as heterochromatin. Moreover, because we and others (Crippa et al. 1993; Trieschmann et al. 1995) have observed maximal stimulation by HMG17 when it is incorporated into chromatin during nucleosome assembly, HMG14/17 might be preferentially incorporated into early replicating DNA relative to late replicating DNA.

In conclusion, the analysis of an abundant nonhistone chromosomal protein, HMG17, has led to its identification as a chromatin-specific transcriptional coactivator. In the future, it will be important to determine the specific mechanism by which HMG17 affects transcription. In this manner, there will be a continuing convergence between the study of transcription factors and the analysis of components of the chromatin template.

\section{Materials and methods}

Synthesis and purification of calf thymus HMG17

A synthetic gene encoding the calf thymus version of HMG17 was prepared by ligation of six oligonucleotides that yielded a DNA segment comprising the sequence depicted in Figure 1A. The codons were optimized for expression in E. coli (Grantham et al. 1980). To ensure efficient translation termination, four successive stop codons were placed at the 3 ' end of the coding sequence. The sequence contained an NdeI site at the initiating Met codon and a BamHI site downstream of the translation stop codons, and the DNA was subcloned into the NdeI and BamHI sites of the pET1la (Novagen) bacterial expression vector to give the plasmid pHMG17.

Recombinant HMG17 was synthesized in E. coli and purified as follows. Except where specifically indicated otherwise, all operations were performed at $4^{\circ} \mathrm{C}$. A freshly transformed colony of pHMG17 in E. coli strain BL21 was grown at $37^{\circ} \mathrm{C}$ in a volume of 1 liter to $A_{600} \mathrm{~nm}=0.7$, and synthesis of HMG17 was induced by the addition of IPTG to $4 \mathrm{~mm}$ final concentration. The growth medium was then incubated at $30^{\circ} \mathrm{C}$ for $30 \mathrm{~min}$. Rifampicin (100 $\mathrm{mg}$; dissolved in $1 \mathrm{ml}$ of methanol) was added to the culture and was incubated at $30^{\circ} \mathrm{C}$ for an additional $3.5 \mathrm{hr}$. The bacteria were pelleted by centrifugation in a Sorvall GSA rotor (4500 rpm; $10 \mathrm{~min}$ ), washed by suspension in phosphatebuffered saline at $\mathrm{pH} 7.4\left(50 \mathrm{ml} ; 3.4 \mathrm{mM} \mathrm{Na}_{2} \mathrm{HPO}_{4}, 1.5 \mathrm{~mm}\right.$ $\mathrm{KH}_{2} \mathrm{PO}_{4}, 137 \mathrm{~mm} \mathrm{NaCl}, 2.6 \mathrm{~mm} \mathrm{KCl}$ ), repelleted in a Sorvall GSA rotor (4500 rpm; $10 \mathrm{~min}$ ), and then resuspended in buffer $\mathrm{A}$ $\left[20 \mathrm{ml} ; 50 \mathrm{~mm}\right.$ HEPES- $\mathrm{K}^{+}$at $\mathrm{pH} 7.6$, containing $50 \mathrm{~mm} \mathrm{NaCl}, 4$ $\mu \mathrm{g} / \mathrm{ml}$ of leupeptin, $4 \mu \mathrm{g} / \mathrm{ml}$ of pepstatin, $4 \mu \mathrm{g} / \mathrm{ml}$ of aprotinin, $4 \mu \mathrm{g} / \mathrm{ml}$ of TPCK $(N$-tosyl-L-phenylalanine chloromethyl ketone), $0.2 \mathrm{~mm}$ phenylmethylsulfonyl fluoride (PMSF), $1 \mathrm{~mm}$ benzamidine, and $1 \mathrm{~mm}$ dithiothreitol (DTT)]. The bacteria were lysed by sonication, and the resulting mixture was subjected to centrifugation in a Sorvall SS-34 rotor $(10,000 \mathrm{rpm} ; 10 \mathrm{~min})$. The majority of the HMG17 was in the insoluble pellet, which was then extracted with $5 \%(\mathrm{vol} / \mathrm{vol})$ perchloric acid [by the addition of $10 \%(\mathrm{vol} / \mathrm{vol})$ perchloric acid to the bacterial pellet of equal volume]. The pellet was suspended by using a Dounce homogenizer with a B pestle. The resulting mixture was incubated for $1 \mathrm{hr}$ on a rotating wheel and was subsequently subjected to centrifugation in a SS-34 rotor $(10,000 \mathrm{rpm} ; 10 \mathrm{~min})$. The supernatant, which contained the solubilized HMG17, was dialyzed twice for $2 \mathrm{hr}$ against 2 liters of buffer A2 $[50 \mathrm{~mm}$ HEPES- $\mathrm{K}^{+}$at $\mathrm{pH} 7.6$, containing $50 \mathrm{~mm} \mathrm{NaCl}, 1 \mathrm{~mm}$ benzamidine, $0.2 \mathrm{~mm}$ PMSF, and $1 \mathrm{~mm}$ DTT] by using low molecular mass cutoff (3500 daltons) dialysis tubing (Spectrapor). After 
dialysis, the solution was clarified by centrifugation in a SS-34 rotor $(10,000 \mathrm{rpm} ; 10 \mathrm{~min})$. The sample (in buffer A2) was then applied to a CM-Sepharose FF column (Pharmacia Biotech) [column volume $=16 \mathrm{ml}$; column dimensions $=1.6 \mathrm{~cm} \times 8 \mathrm{~cm}$ (diameter $\times$ length; Pharmacia Biotech XK 16/20 column); flow rate $=1 \mathrm{ml} / \mathrm{min}$ fraction size $=1 \mathrm{ml}$. The column was washed with $48 \mathrm{ml}$ (three column volumes) of buffer $\mathrm{A} 2$, and protein was eluted with a linear salt gradient of $0.05-1.0 \mathrm{M} \mathrm{NaCl}$ in buffer A2 over $80 \mathrm{ml}$ (five column volumes). HMG17 eluted from the column at $\sim 400 \mathrm{~mm} \mathrm{NaCl}$, as determined by the conductivity of the HMG17-containing fractions. The peak fractions (as determined by SDS-PAGE) were subjected to dialysis for $2 \mathrm{hr}$ followed by $12 \mathrm{hr}$ against 2 liters of storage buffer [10 mM HEPES- $\mathrm{K}^{+}$at $\mathrm{pH} 7.6$, containing $10 \mathrm{~mm} \mathrm{KCl}, 0.5 \mathrm{~mm}$ EGTA, $1.5 \mathrm{mM} \mathrm{MgCl} 2,10 \%$ (vol/vol) glycerol, $10 \mathrm{~mm} \beta$-glycerophosphate, $0.2 \mathrm{mM}$ PMSF, $1.0 \mathrm{~mm}$ DTT]. The protein was frozen in liquid nitrogen and stored at $-80^{\circ} \mathrm{C}$. Approximately $1.5 \mathrm{mg}$ of purified HMG17 was obtained from a 1-liter culture, as determined by the BCA protein assay (Pierce) by using bovine serum albumin as a reference.

The purified, recombinant HMG17 was characterized by SDS-PAGE (Fig. 1B), amino acid sequence analysis, and mass spectroscopy. The amino-terminal sequence was determined to be P-K-R-K-A-E, which indicated that the initiating Met residue had been removed, as occurs with the native protein (Walker et al. 1977; Walker 1982). Determination of the molecular mass of the protein by ion spray mass spectroscopy confirmed the loss of the initiating Met residue and the integrity of the polypeptide. Hence, the primary amino acid sequence of $E$. coli-synthesized HMG17 was identical to that of native calf thymus HMG17.

\section{Protein purification}

Core histones were purified from Drosophila embryos as described by Bulger and Kadonaga (1994). Histone $\mathrm{Hl}$ was purified from Drosophila embryos by the method of Croston et al. (1991). GAL4-VP16 was synthesized in E. coli and purified to $\sim 75 \%$ homogeneity as described by Chasman et al. (1989). GAL4(1-147) was synthesized in E. coli and purified to $\sim 95 \%$ homogeneity by the method of Lin et al. (1988). Native calf thymus HMG17 was purified as follows. Calf thymus nuclei were extracted with $0.35 \mathrm{M} \mathrm{NaCl}$ and then subjected to chromatography on a S-Sepharose resin (Pharmacia Biotech), from which the protein eluted at $\sim 0.5-0.6 \mathrm{M} \mathrm{NaCl}$. The HMG17 was then purified to apparent homogeneity (Fig. 1B) by chromatography on a Mono-S resin (Pharmacia Biotech), from which the protein eluted at $\sim 0.6-0.7 \mathrm{M} \mathrm{NaCl}$.

\section{Chromatin assembly}

Chromatin was assembled by using the S-190 extract derived from Drosophila embryos, with slight modification of methodology that has been described previously (Kamakaka et al. 1993; Bulger and Kadonaga 1994). In a typical assembly reaction, S-190 extract ( $300 \mu \mathrm{l})$ was incubated with purified Drosophila core histones (5 $\mu \mathrm{g}$ ), HMG17 or buffer (as indicated), and GAL4 derivative or buffer (as indicated) in a total volume of $423 \mu \mathrm{l}$ at $4^{\circ} \mathrm{C}$ for $30 \mathrm{~min}$. Plasmid DNA $(10 \mu \mathrm{g} / \mathrm{ml})$, ATP $(3 \mathrm{~mm})$, creatine phosphate (30 mM; Sigma P 6502), creatine kinase (1 $\mu \mathrm{g} / \mathrm{ml}$; Sigma C 3755), and $\mathrm{MgCl}_{2}$ (8.3 $\mathrm{mm}$ ) were added to the indicated final concentrations in a final volume of $500 \mu \mathrm{l}$, and the chromatin assembly reaction was carried out at $27^{\circ} \mathrm{C}$ for $5.5 \mathrm{hr}$. In the experiments shown in this paper, exogenous histone $\mathrm{Hl}$ was not included in the assembly reactions. Similar transcriptional results were obtained, however, when $\mathrm{Hl}$ was included (data not shown). Where indicated, the newly assembled chromatin was purified by $30 \%-50 \%$ (wt/vol) sucrose gradient sedimentation, as described elsewhere (Kamakaka et al. 1993; Bulger and Kadonaga 1994).

By Western blot analysis with antibodies directed against calf thymus HMG17, an HMG17-related species was not identified in the Drosophila S-190 extract (data not shown). A homolog of HMG14/17 has not yet been identified definitively in Drosophila. Yet, homologs of other abundant chromosomal proteins, including $\mathrm{Hl}, \mathrm{HMGl} / 2, \mathrm{HMG}-\mathrm{I} /-\mathrm{Y}, \mathrm{RCCl}$, and $\mathrm{HP}-1$, have been found in Drosophila. Furthermore, it has been suggested (Wagner et al. 1992) that the Drosophila protein HMG-D/-Z has characteristics similar to those of HMG14/17. Hence, it would be not surprising if a homolog of HMG14/17 were identified in Drosophila. For practical purposes in this work, we have found that there is not a detectable amount of HMG14/17 activity in the S-190 assembly extract. For example, in the absence of exogenous HMG17, a slower migrating species was not observed in the native nucleoprotein gel shift assay (Fig. 2D).

\section{Analysis of the chromatin}

Micrococcal nuclease digestion and DNA supercoiling analyses were carried out as described previously (Kamakaka et al. 1993; Bulger and Kadonaga 1994). Electron microscopy of chromatin was performed as described elsewhere (Thoma et al. 1979; Kamakaka et al. 1993). Characterization of core particles by native nucleoprotein gel electrophoresis was performed by extensive digestion of sucrose gradient-purified chromatin by micrococcal nuclease followed by electrophoresis in a $5 \%$ (wt/vol) nondenaturing polyacrylamide gel, by using conditions similar to those described by Crippa et al. (1992). The protein composition of sucrose gradient-purified chromatin was determined by $15 \%$ SDS-PAGE followed by staining with Coomassie brilliant blue R-250.

\section{In vitro transcription}

In vitro transcription analysis of chromatin templates was carried out immediately after chromatin assembly as described by Pazin et al. (1994). The plasmid $\mathrm{pG}_{5} \mathrm{E} 4 \mathrm{~T}$ contains five GAL4binding sites upstream of the TATA box and minimal promoter of the adenovirus E4 promoter (Lin et al. 1988), whereas the plasmid $\mathrm{pG}_{0} \mathrm{E} 4 \mathrm{~T}$ is identical to $\mathrm{pG}_{5} \mathrm{E} 4 \mathrm{~T}$, except that it does not contain any GAL4-binding sites. HeLa nuclear extracts were prepared as described by Dignam et al. (1983; except that the extraction was performed with $0.42 \mathrm{M} \mathrm{KCl}$ instead of $0.42 \mathrm{M}$ $\mathrm{NaCl}$, and the basal transcription factors were precipitated with $2.1 \mathrm{M}$ ammonium sulfate to remove endogenous HMG14/ 17 proteins, which remain in the supernatant. After suspension of the pellet and removal of the ammonium sulfate by dialysis, the resulting transcription extracts were frozen in aliquots in liquid nitrogen and stored at $-80^{\circ} \mathrm{C}$. The Drosophila high salt extract was prepared from nuclei (derived from embryos collected from 0 to $12 \mathrm{hr}$ after fertilization; see Kamakaka and Kadonaga 1994) according to the identical procedure that was used for the HeLa extract. The Drosophila soluble nuclear fraction was prepared as described elsewhere (Kamakaka et al. 1991; Kamakaka and Kadonaga 1994).

The mapping of the $3^{\prime}$ ends of the in vitro-transcribed RNA was performed as described previously (Meulia et al. 1992). The 3 ' end-labeled probe was prepared as follows. The template DNA (GAL-TATA-MG; Krumm et al. 1995) was digested 15 bp downstream of the transcription initiation site with AccI. The ends were filled in with the large fragment of $E$. coli DNA polymerase I in the presence of dGTP and $\left[\alpha^{-32} \mathrm{P} \mid \mathrm{dCTP}\right.$. The DNA was then digested with $\mathrm{SacI}$ and gel purified to give a double- 
stranded, 3 '-end-labeled AccI-SacI fragment that corresponds to transcribed sequences from +15 to +767 relative to the RNA start site.

The transcriptional capacity of the HMG17-containing chromatin was comparable to that of nonchromatin templates (either histone-free naked DNA or mock-assembled templates where exogenous core histones were omitted during assembly with the S-190 extract). With HeLa transcription extracts, the amount of GAL4-VP16-activated transcription from HMG17containing chromatin was $\sim 32 \%$ of that from a nonchromatin control. With the Drosophila soluble nuclear fraction, the amount of GAL4-VP16-activated transcription from HMG17containing chromatin was $\sim 40 \%$ of that from a nonchromatin control (data not shown). All experiments, including data not shown, were carried out at least three times (but typically, several times/ with different preparations of chromatin assembly extracts and transcription factors to ensure reproducibility of the data. The transcription data were quantitated by using a Fuji PhosphorImager. In many $(>30)$ independent experiments, the magnitude of the transcriptional stimulation by HMG 17 (at 10 molecules/ $180 \mathrm{bp}$ during assembly) typically varied from $\sim 7$ - to 40 -fold, and this variation was largely attributable to inaccuracies in the determination of the low level of transcription observed in the absence of HMG17.

\section{Acknowledgments}

We are grateful to Bruno Zimm, Rohinton Kamakaka, Jessica Tyler, Beth Blackwood, Mike Bulger, Catherine George, Mike Pazin, Lee Kraus, Tom Burke, Alan Kutach, and Takashi Ito for critical reading of the manuscript. We thank Matt Williamson for carrying out the amino-terminal amino acid sequence analysis of the recombinant HMG17; Gary Suizdak for analyzing the recombinant HMG17 by ion spray mass spectroscopy /facility supported by the Lucille P. Markey Charitable Trust and by National Institutes of Heath grant S10 RR072731; Mike Bulger for performing the electron microscopy; Catherine George, Tom Burke, and Lucy DeVito for the gift of purified basal transcription factors; Michael Bustin for the gift of antibodies against HMG 17; and Beverly Emerson, Mark Groudine, and Rohinton Kamakaka for helpful advice. A.K. was supported by a Special Fellowship from the Leukemia Society of America and a grant from the National Cancer Institute (CA54337) to Mark Groudine. J.T.K. is a Presidential Faculty Fellow. This work was supported by grants from the National Institutes of Health, the National Science Foundation, and the Council for Tobacco Research to J.T.K.

The publication costs of this article were defrayed in part by payment of page charges. This article must therefore be hereby marked "advertisement" in accordance with 18 USC section 1734 solely to indicate this fact.

\section{References}

Albright, S.C., J.M. Wiseman, R.A. Lange, and W.T. Garrard. 1980. Subunit structures of different electrophoretic forms of nucleosomes. J. Biol. Chem. 255: 3673-3684.

Alfonso, P.J., M.P. Crippa, J.J. Hayes, and M. Bustin. 1994. The footprint of chromosomal proteins HMG-14 and HMG-17 on chromatin subunits. I. Mol. Biol. 236: 189-198; erratum 239: 436.

Almouzni, G. and M. Méchali. 1988. Assembly of spaced chromatin: involvement of ATP and DNA topoisomerase activity. EMBO J. 7: 4355-4365.

Almouzni, G., M. Méchali, and A.P. Wolffe. 1991. Transcription complex disruption caused by a transition in chromatin structure. Mol. Cell. Biol. 11: 655-665.
Baer, B.W. and D. Rhodes. 1983. Eukaryotic RNA polymerase II binds to nucleosome cores from transcribed genes. Nature 301: 482-488.

Bulger, M. and J.T. Kadonaga. 1994. Biochemical reconstitution of chromatin with physiological nucleosome spacing. Methods Mol. Genet. 5: 241-262.

Bustin, M., D.A. Lehn, and D. Landsman. 1990. Structural features of the HMG chromosomal proteins and their genes. Biochim. Biophys. Acta 1049: 231-243.

Chasman, D.I., J. Leatherwood, M. Carey, M. Ptashne, and R.D. Kornberg. 1989. Activation of yeast polymerase Il transcription by herpes VP16 and GAL4 derivatives in vitro. Mol Cell. Biol. 9: 4746-4749.

Cook, G.R., P. Yau, H. Yasuda, R.R. Traut, and E.M. Bradbury. 1986. High mobility group protein 17 cross-links primarily to histone $\mathrm{H} 2 \mathrm{~A}$ in the reconstituted HMG 17-nucleosome core particle complex. I. Biol. Chem. 261: 16185-16190.

Crippa, M.P, P.J. Alfonso, and M. Bustin. 1992. Nucleosome core binding region of chromosomal protein $\mathrm{HMG}-17$ acts as an independent functional domain. I. Mol. Biol. 228: 442-449.

Crippa, M.P., L. Trieschmann, P.J. Alfonso, A.P. Wolffe, and M. Bustin. 1993. Deposition of chromosomal protein HMG-17 during replication affects the nucleosomal ladder and transcriptional potential of nascent chromatin. EMBO $J$. 12: 3855-3864.

Croston, G.E., L.M. Lira, and I.T. Kadonaga. 1991. A general method for the purification of $\mathrm{Hl}$ histones that are active for repression of basal RNA polymerase II transcription. Protein Expression Purification 2: 162-169.

Dignam, J.D., R.M. Lebovitz, and R.G. Roeder. 1983. Accurate transcription initiation by RNA polymerase II in a soluble extract from isolated mammalian nuclei. Nucleic Acids Res. 11: 1475-1489.

Ding, H.-F., S. Rimsky, S.C. Batson, M. Bustin, and U. Hansen. 1994. Stimulation of RNA polymerase II elongation by chromosomal protein HMG-14. Science 265: 796-799.

Dorbic, T. and B. Wittig. 1987. Chromatin from transcribed genes contains HMG17 only downstream from the starting point of transcription. EMBO I. 6: 2393-2399.

Drew, H.R. 1993. Reconstitution of short-spaced chromatin from the histone octamer and either HMG-14,17 or histone H1. J. Mol. Biol. 230: 824-836.

Einck, L. and M. Bustin. 1985. The intracellular distribution and function of the high mobility group chromosomal proteins. Exp. Cell. Res. 156: 295-310.

Felsenfeld, G. 1992. Chromatin as an essential part of the transcriptional mechanism. Nature 355: 219-224.

Germond, J.E., B. Hirt, P. Oudet, M. Gross-Bellard, and P. Chambon. 1975. Folding of the DNA double helix in chromatin-like structures from simian virus 40 . Proc. Natl. Acad. Sci. 72: 1843-1847.

Glikin, G.C., I. Ruberti, and A. Worcel. 1984. Chromatin assembly in Xenopus oocytes: In vitro studies. Cell 37: 33-41.

González, P.J. and E. Palacián. 1990. Structural and transcriptional properties of different nucleosomal particles containing high mobility group proteins 14 and 17 (HMG 14/17). I. Biol. Chem. 265: 8225-8229.

Goodwin, G.H. and C.G.P. Mathew. 1982. Role in gene structure and function. In The HMG chromosomal proteins (ed. E.W. Johns), pp. 193-221. Academic Press, New York.

Goodwin, G.H., J.M. Walker, and E.W. Johns. 1978. The high mobility group (HMG) nonhistone chromosomal proteins. In The cell nucleus (ed. H. Busch), vol. 6, pp. 181-219. Academic Press, New York.

Grantham, R., C. Gautier, M. Gouy, R. Mercier, and A. Pave. 1980. Codon catalog usage and the genome hypothesis. $\mathrm{Nu}$ - 
cleic Acids Res. 8: r49-r62.

Hawley, D.K. and R.G. Roeder. 1985. Separation and partial characterization of three functional steps in transcription initiation by human RNA polymerase II. I. Biol. Chem. 260: 8163-8172.

1987. Functional steps in transcription initiation and reinitiation from the major late promoter in a HeLa nuclear extract. J. Biol. Chem. 262: 3452-3461.

Kadonaga, J.T. 1990. Assembly and disassembly of the Drosophila RNA polymerase II complex during transcription. I. Biol. Chem. 265: 2624-2631.

Kamakaka, R.T. and J.T. Kadonaga. 1994. The soluble nuclear fraction, a highly efficient transcription extract from Drosophila embryos. Methods Cell Biol. 44: 225-235.

Kamakaka, R.T., C.M. Tyree, and J.T. Kadonaga. 1991. Accurate and efficient RNA polymerase II transcription with a soluble nuclear fraction derived from Drosophila embryos. Proc. Natl. Acad. Sci. 88: 1024-1028.

Kamakaka, R.T., M. Bulger, and J.T. Kadonaga. 1993. Potentiation of RNA polymerase II transcription by Gal4-VP16 during but not after DNA replication and chromatin assembly. Genes \& Dev. 7: 1779-1795.

Krumm, A., L.B. Hickey, and M. Groudine. 1995. Promoterproximal pausing of RNA polymerase II defines a general rate-limiting step after transcription initiation. Genes \& Dev. 9: 559-572.

Kuehl, L., B. Salmond, and L. Tran. 1984. Concentrations of high-mobility-group proteins in the nucleus and cytoplasm of several rat tissues. J. Cell Biol. 99: 648-654.

Landsman, D. and M. Bustin. 1991. Assessment of the transcriptional activation potential of the HMG chromosomal proteins. Mol. Cell. Biol. 11: 4483-4489.

Landsman, D., E. Mendelson, S. Druckmann, and M. Bustin. 1986. Exchange of proteins during immunofractionation of chromatin. Exp. Cell Res. 163: 95-102.

Lee, J.W., H.-S. Choi, J. Gyuris, R. Brent, and D.D. Moore. 1995 Two classes of proteins dependent on either the presence or absence of thyroid hormone for interaction with the thyroid hormone receptor. Mol. Endocrinol. 9: 243-254.

Lin, Y.-S., M.F. Carey, M. Ptashne, and M.R. Green. 1988. GAL4 derivatives function alone and synergistically with mammalian activators in vitro. Cell 54: 659-664.

Mardian, J.K.W., A.E. Paton, G.J. Bunick, and D.E. Olins. 1980. Nucleosome cores have two specific binding sites for nonhistone chromosomal proteins HMG 14 and HMG 17. Science 209: 1534-1536.

Meulia T., A. Krumm, C. Spencer, and M. Groudine. 1992. Sequences of the human c-myc promoter affect the elongation and premature termination of transcripts initiated from the upstream P1 promoter. Mol. Cell. Biol. 12: 4590-4600.

Noll, M. and R.D. Kornberg. 1977. Action of micrococcal nuclease on chromatin and the location of histone Hl. J. Mol. Biol. 109: 393-404.

Paranjape, S.M., R.T. Kamakaka, and J.T. Kadonaga. 1994. Role of chromatin structure in the regulation of transcription by RNA polymerase II. Annu. Rev. Biochem. 63: 265-297.

Paton, A.E., E. Wilkinson-Singley, and D.E. Olins. 1983. Nonhistone nuclear high mobility group proteins 14 and 17 stabilize nucleosome core particles. J. Biol. Chem. 258: 1322113229.

Pazin, M.J., R.T. Kamakaka, and J.T. Kadonaga. 1994. ATP-dependent nucleosome reconfiguration and transcriptional activation from preassembled chromatin templates. Science 266: 2007-2011.

Postnikov, Y.V., V.V. Shick, A.V. Belyavsky, K.R. Khrapko, K.L. Brodolin, T.A. Nikolskaya, and A.D. Mirzabekov. 1991. Dis- tribution of high mobility group proteins $1 / 2, \mathrm{E}$ and $14 / 17$ and linker histones $\mathrm{H1}$ and $\mathrm{H} 5$ on transcribed and non-transcribed regions of chicken erythrocyte chromatin. Nucleic Acids Res. 19: 717-725.

Sadowski, I., J. Ma, S. Triezenberg, and M. Ptashne. 1988. GAL4-VP16 is an unusually potent transcriptional activator. Nature 335: 563-564.

Sandeen, G., W.I. Wood, and G. Felsenfeld. 1980. The interaction of high mobility proteins HMG14 and 17 with nucleosomes. Nucleic Acids Res. 8: 3757-3778.

Shick, V.V., A.V. Belyavsky, and A.D. Mirzabekov. 1985. Primary organization of nucleosomes. Interaction of non-histone high mobility group proteins 14 and 17 with nucleosomes, as revealed by DNA-protein crosslinking and immunoaffinity isolation. J. Mol. Biol. 185: 329-339.

Simpson, R.T., F. Thoma, and J.M. Brubaker. 1985. Chromatin reconstituted from tandemly repeated cloned DNA fragments and core histones: A model system for study of higher order structure. Cell 42: 799-808.

Swerdlow, P.S. and A. Varshavsky. 1983. Affinity of HMGl7 for a mononucleosome is not influenced by the presence of ubiquitin-H2A semihistone but strongly depends on DNA fragment size. Nucleic Acids Res. 11: 387-401.

Thoma, F., T. Koller, and A. Klug. 1979. Involvement of histone $\mathrm{Hl}$ in the organization of the nucleosome and of the saltdependent superstructures of chromatin. I. Cell Biol. 83: 403-427.

Tremethick, D.J. 1994. High mobility group proteins 14 and 17 can space nucleosomal particles deficient in histones $\mathrm{H} 2 \mathrm{~A}$ and $\mathrm{H} 2 \mathrm{~B}$ creating a template that is transcriptionally active. J. Biol. Chem. 269: 28436-28442.

Tremethick, D.J. and H.R. Drew. 1993. High mobility group proteins 14 and 17 can space nucleosomes in vitro. J. Biol. Chem. 268: 11389-11393.

Trieschmann, L., P.J. Alfonso, M.P. Crippa, A.P. Wolffe, and M. Bustin. 1995. Incorporation of chromosomal proteins HMG14/HMG-17 into nascent nucleosomes induces an extended chromatin conformation and enhances the utilization of active transcription complexes. EMBO I. 14: 1478-1489.

Tyree, C.M., C.P. George, L.M. Lira-DeVito, S.L. Wampler, M.E. Dahmus, L. Zawel, and J.T. Kadonaga. 1993. Identification of minimal set of proteins that is sufficient for accurate initiation of transcription by RNA polymerase II. Genes \& Dev. 7: 1254-1265.

van Holde, K.E. 1989. Chromatin. Springer-Verlag, New York.

Wagner, C.R., K. Hamana, and S.C.R. Elgin. 1992. A high-mobility group protein and its cDNAs from Drosophila melanogaster. Mol. Cell. Biol. 12: 1915-1923.

Walker, J.M. 1982. Primary structures. In The HMG chromosomal proteins (ed. E.W. Johns), pp. 193-221. Academic Press, New York.

Walker, J.M., J.R.B. Hastings, and E.W. Johns. 1977. The primary structure of a non-histone chromosomal protein. Eur. I. Biochem. 76: 461-468.

Weisbrod, S. 1982. Active chromatin. Nature 297: 289-295.

Wolffe, A.P. 1992. Chromatin: Structure and function. Academic Press, San Diego, CA.

Yau, P., B.S. Imai, A.W. Thorne, G.H. Goodwin, and E.M. Bradbury. 1983. Effect of HMG protein 17 on the thermal stability of control and acetylated HeLa oligonucleosomes. $\mathrm{Nu}$ cleic Acids Res. 11: 2651-2664. 


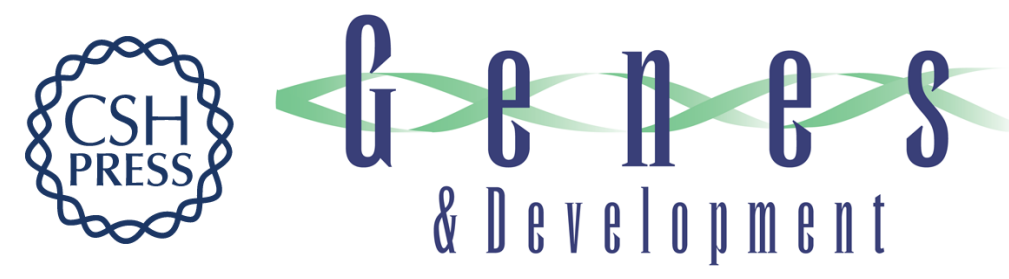

\section{HMG17 is a chromatin-specific transcriptional coactivator that increases the efficiency of transcription initiation.}

S M Paranjape, A Krumm and J T Kadonaga

Genes Dev. 1995, 9:

Access the most recent version at doi:10.1101/gad.9.16.1978

References This article cites 55 articles, 24 of which can be accessed free at: http://genesdev.cshlp.org/content/9/16/1978.full.html\#ref-list-1

License

Email Alerting

Receive free email alerts when new articles cite this article - sign up in the box at the top Service right corner of the article or click here.

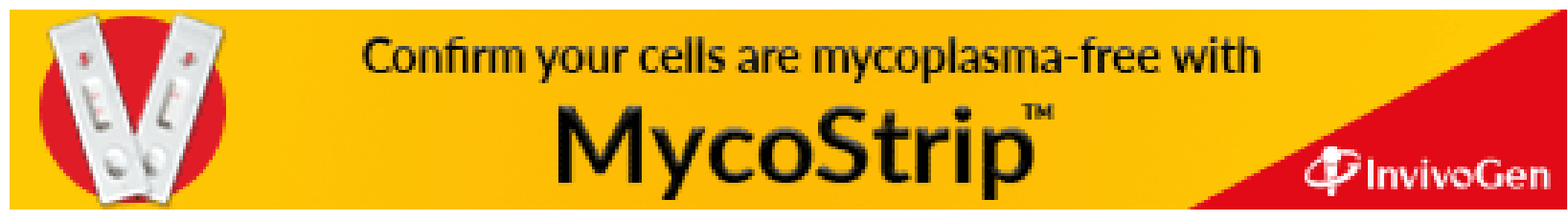

